\title{
Impact of Self-Regulation and Open Learner Model on Learning Achievement in Blended Learning Environment
}

\author{
Nilubon Tongchai
}

\begin{abstract}
This paper describes the use of the concept of an Open Learner Model as a means by which students can be supported in their reflection on their learning at University level. The work is situated within a "blended" learning environment consisting of both classroom teaching and an online learning management system (Moodle). The topic studied by the students is a second year module on "Computer System and Architecture". This work focuses on how blended learning has an impact on learning achievement comparing to the normal classroom learning with the same learning contents. The results show that students from blended learning environment have a bigger difference in mean scores comparing between pre-test and post-test. Furthermore, the significant correlations between AllTest, NetScore and Post-test can be inferred that this way of learning, through responsibility and self-regulation - the way of knowing themselves - for lesson activities of learners is a key factor for successful learning.
\end{abstract}

Index Terms-Blended learning, self-regulated learning, learner model, open learner model.

\section{INTRODUCTION}

There are significant bodies of research on both the utility of encouraging students to be self-regulated learners [1], [2] and on the benefits of encouraging students to help each other [3], [4]. There is also a significant need to improve the effectiveness of online courses [5], [6]. This is particularly so for many educational systems that struggle to provide sufficient teachers for the growing demand for high quality educational experiences designed to lift the standard of education [7].

For example, as in many countries, the Thai government is concerned that there are insufficient teachers - especially in the area of Science and Technology [8]. The Tenth National Economic and Social Development Plan (2007-2011) of Thailand's Ministry of Education proposed to use innovative technology for learning and teaching in order to relieve the situation. To ensure such a plan can be achieved there are many practical difficulties to overcome including how to ensure that there are sufficient high quality technological solutions, adequate means to distribute them and methods of ensuring their sustainability and further development [9]-[11].

The application of approaches that promote both self-regulation and cooperative/collaborative student behavior can assist in mitigating any lack of sufficient teaching expertise creating learners capable of working

Manuscript received July 29, 2014; revised December 1, 2014

N. Tongchai is with Computer Science Department, Kanchanaburi Rajabhat University, Thailand (e-mail: nilubon.tongchai@kru.ac.th). together in a self-regulated manner is an educational goal worth pursuing [1], [2]. This is arguably true even in situations in which learners ask their friends for answers or even look for answers on the internet even though the answers they find might be wrong.

The approach taken in this research is to utilize a web-based learning platform which allows learners to exchange information with either friends or teachers and to see their learning record. The learning record is a model of the learner's understanding - a learner model. It is open to inspection by the learner - hence the learner model is an open learner model [9]-[11]. Such an open learner model (OLM) supports self-regulation for learners to become aware of how well they perform on particular tasks: externalizing the kinds of activities they might engage in next, who might help them and who might need their help, and so on [12].

The main aim of the research being undertaken is therefore to examine the benefits of opening the learner model to students in blended learning contexts. This particular paper provides evidence that a blended learning environment featuring an Open Learner Model can enhance learning performance. Future work will seek to examine the ways in which accessing the Open Learner Model can lead to improved learning.

\section{THE LEARNING ENVIRONMENT}

The courseware for 'Computer System and Architecture' was delivered via the Moodle LMS on the university website with URL http://elearningcoit.kru.ac.th in semester 3/2010 Fig. 1 shows what learners see after logging in to the online learning system. Within this learning environment, learners can access the course materials including teaching slides and handouts which have already been used in the classroom. Learners are also assigned to do some activities online such as exercises, homework, lesson summaries, individual and group work, etc.

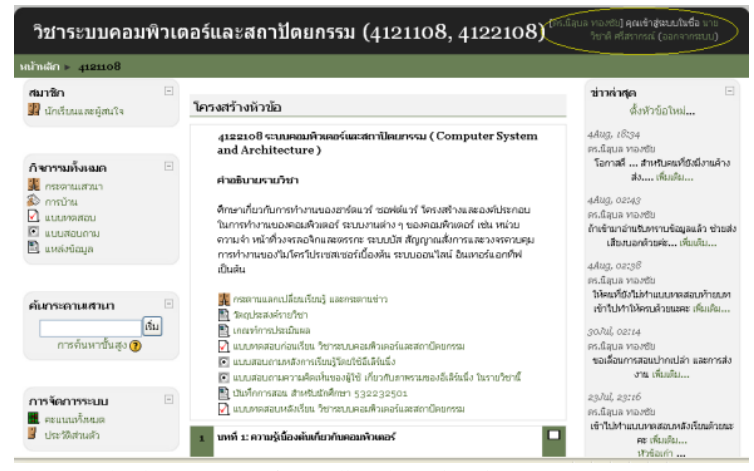

Fig. 1. The home page for online learning in computer system and architecture subject. 
1) "Personal Information" contains information about each student - where they are from, email address, all subjects for which they are already registered, the latest access time, role, and study group.

2) "Edit information" allows student to change their personal information, and to manage which parts they want to show and which parts they want to set as private.

3) "Post" shows the messages that each student has posted on the web-board both as an owner of the post and as a participant of the post.

4) "Blog" allow students to have their own space to create and share their information as a blog.

5) "Note" is a section to show all short messages that are sent from and to each student.

6) "Activity Reports" is a section that reports all information about activities that each particular student attends. Example of activities are do pre-test, download learning document, do homework, do lesson exercises, etc. For the pre-test, it will show date, time, duration score and feedback as a suggestion of each score, etc.

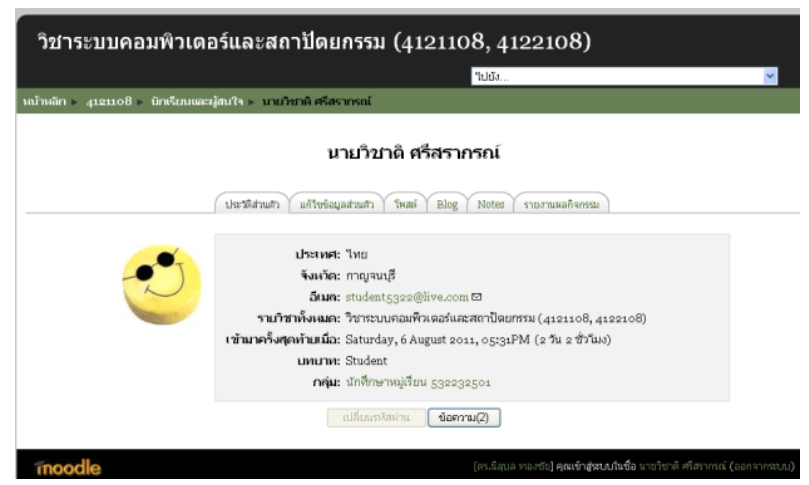

Fig. 2. Information of individual learner about history of their learning activities.

Information about learning activities is kept in the learner model (see Fig. 2) and this can be reflected back to learners and teachers by the time requested or through an assignment. This information can be used either to seek help or to give some help to others via the web-board and short messages. Moreover students can receive comments from teachers on their work and students can compare their work with that of others - who may do either better or worse than them - to improve their work.

Information of participation in exercises, homework, assignments at each stage of learning together with the results from the pre-test and post-test might help teachers to understand the learner's situation and give timely support to learners. The information in the learner model can be used either by teachers or learners to reflect on how well learners perform [9]-[14]. Issues about student self-regulation and their self-awareness of their knowledge on learning and metacognition is planned to be the focus of further studies to see how self-regulation and self-awareness have an impact on learning achievement.

\section{REVIEW OF LITERATURES}

\section{A. Blended Learning}

Blended learning is a hybrid of classroom and online learning that includes some of the conveniences of online courses without the complete loss of face-to-face contact. Comparing to either online or classroom base learning alone, blended learning has evidence of learning achievement as a pre-test differences significantly higher than either traditional classroom or online based learning with a large effect size [5]. Learning environment alone might not be the key to success on learning achievement, characteristics of successful students that should be further concerned are interest in the material taught, self-motivation, independent and self-directed learner, critical thinker, family support, positive and timely feedback, accepts responsibility for own learning, organized, and practical knowledge in the use of computers. One of the successful blended learning models described by Martyn [6] consists of an initial face-to-face meeting, weekly online assessments and synchronous chat, asynchronous discussions, e-mail, and a final face-to-face meeting with a proctored final examination.

\section{B. Self-Regulated Learner}

Self-regulated learners are ones who perform educational tasks with confidence, diligent, aware of their skills, proactively sought for information and systematic thinking to master the specific learning task with no fear from obstacle. A common conceptualized of self-regulated learners are ones who metacognitively, motivationally, behaviorally perform in their own learning. In the metacognitive processes, these learners should regulate plan, set goal, organized, monitor and evaluate themselves. In the motivational processes, these learners have high self-efficacy, self-attribution and intrinsic task interest. In behavioral processes, these learners can select structure and create environment that optimize their learning. Systematic use of metacognitive, motivational, and behavioral is a key feature for becoming a self-regulated learner. [1]

\section{Learner Models That Support Metacognitive Activities}

Learner models (or student models) are used to build adaptive educational systems for learners (or students). Learner models support the tracking of a student's changing knowledge during the use of an ITS (Intelligent Tutoring System). However, the idea of reflecting the information about learning back to the learner is used in this research [12]-[15].

The idea of giving students information about their overall state of knowledge is related to the provision of feedback but it is not quite the same as providing "optimal" feedback according to the normal view of feedback. The main purpose of giving feedback is often seen as providing comments that are precise, accurate, timely and necessary [16], [17]. A learner who inspects a learner model (OLM) has to direct their attention to what they feel is most pertinent for them perhaps a cognitively demanding activity but also one that can be seen as part of a student being responsible for their own learning, being a self-regulated learner [1], [6]. However, even if a student finds it difficult to pick out the most important issue, a student does get some feedback, and Kulhavy and Wager [18] claimed that giving some feedback is better than no feedback.

An OLM is considered to be an aid to reflection. It can convey - directly or indirectly-how well a student performed 
on a particular task at least so that they may have a feeling for their strengths and weaknesses before continuing to do the next task [17]. It can provoke the learner to think about the truth or falsity of the information conveyed, and in doing this; reflect upon a number of issues including, perhaps, that of how their learning is progressing. Bull and Nghium [9] stated that "the important reason for rendering the learner model accessible is to help student better understand their learning 'opening' the learner model to the modellee offers a source of information about their relationship with a target domain which is otherwise unavailable, encourage them to reflect on their beliefs and on the learning process."

In order to utilize an OLM in practice, the definition of 'opening' has to be decided upon. It has to make clear whether it means open to only see but not change, see and change to some extent, or can see and change without any restrictions. It is then necessary to define what is opened to the user, who can access the model, how much information they can access and which external representation should be used to reflect back the learning information to users, and so on. In this paper, information relevant to the learning of individual students is kept in the learner model and reflected back to learners using Moodle LMS. The information of how well learners perform is externalized as a score and a textual explanation is provided of how well learners perform in particular tasks of homework, exercises and assignments.

\section{Roles of External Representation in OLM}

Providing the right amount of information to suit the target group may encourage them to behave in more effective ways, for instance, providing learners with information about their performance may help them to know how to react to their friends and their tutor.

As already stated, one of the useful features of the learner model is to keep information about particular learners which may help the inspector (which can be the system, a student or a teacher) to know how well learners perform. There are many aspects of such an interaction within the system that need to be designed carefully - interaction between human and system, interaction from one human to another via the system, etc. During the interaction, there might also be some exchange of beliefs between the learners. This too has to be designed for To exchange beliefs, we have to be concerned with which information is made available and how to represent it.

\section{Methodology}

\section{A. Research Participation}

The context of the research is the subject of 'Computer System and Architecture' studied by 2 nd year computer science students at Kanchanaburi Rajabhat University. Two groups of students were required - all the students enrolled in semester 1 (26) and semester 3 (15) agreed to participate. The semester 1 group were assigned to study in a classroom based learning environment while the semester 3 group of 15 students were assigned to study in a blended learning environment which consisted of a combination of classroom learning together with the use of Moodle LMS.

\section{B. Materials}

The courseware for 'Computer System and Architecture' was delivered via the Moodle LMS on the university website http://elearningcoit.kru.ac.th in semester 3/2010. It was designed to have very similar content to that provided for the students using classroom-based learning in semester 1/2010. For online learning, the contents set up on Moodle LMS consist of explanations, assignments, homework, exercises, lesson tests, etc. This additional content on Moodle was designed to be as close as possible to the content used in the classroom-based learning environment.

The main differences are

1) Each lesson has a multiple choice test that can be taken as many times as, and when, the student wants

2) A learning space in which to share information, questions and answers with both friends and teacher anytime the student wants.

So learners and teachers can use many channels to communicate and exchange their beliefs via the provided website. Since each student action is recorded and stored in the 'learner model' learners or teachers can view the learner model according to their access rights.

An 80 item test was designed to measure the extent to which the participants knew the course content and make judgments based on this knowledge. The 80 item test was developed from testing a hundred items over two earlier semesters to remove questions that were too easy and too hard

\section{Procedure}

The pre-test was applied at the start of the semester in the first session with the students from both groups. Students were given 90 minutes to do the test. The post test was applied during the last session of the semester. Students were given the same time to carry it out.

A 27 item questionnaire was administered to those completing the on-line version to assess user satisfaction.

Both versions of the course ran for 16 weeks. Each week involved 50 minutes of work in each of four timetabled periods. Learners were expected to spend approximately 5 periods a week on homework, exercises and self-directed learning.

The primary approach for analyzing the results was to use the difference between pre-test and post-test as a measure of learning achievement. There was the additional potential to examine student's progress to see whether there is any relationship between the various observations that the system holds - including the various scores (pre-test, assignments, homework, post-test and the final grading score) and also the questions asked, how often an exercise is done and so on. Similar data could, in principle, be collected from the classroom-based approach but only classroom behavior can be observed and, inevitably, it is much more difficult for the teacher to record the data.

\section{RESUlTS}

The first question addressed is whether the move from classroom-based learning to a blended version of the same course leads to improved learning. The two groups were, as stated above, 26 2nd year students taking the 'Computer System and Architecture' course in a classroom-based form 
during semester $1 / 2010$ and 15 2nd year students taking the same course in blended form using Moodle LMS during semester 3/2010. The 80 item multiple choice tests was administered as both a pre-test and a post-test scores to both groups and the results analyzed.

TABLE I: THE AVERAGE (MEAN) MEAN SCORES AND MEAN DIFFERENCES
\begin{tabular}{|c|c|c|c|c|}
\hline Group & $N$ & \multicolumn{2}{|c|}{$\begin{array}{c}\text { Mean score } \\
\text { difference }\end{array}$} \\
\cline { 3 - 4 } & Pre-test & Post-test & 12.88 \\
\hline $\begin{array}{c}\text { Semester } \\
1 / 2010\end{array}$ & 26 & 46.39 & 59.28 & 16.33 \\
\hline $\begin{array}{c}\text { Semester } \\
3 / 2010\end{array}$ & 15 & 54.83 & 71.17 & \\
\hline
\end{tabular}

As shown in Table I, both groups of students have a mean post-test score which is higher than the mean for the pre-test score. This suggests that learners in both conditions have made learning gains. Moreover, focusing on the mean difference, the results indicate that learners in semester $3 / 2010$ have made a larger improvement in their scores (difference in mean scores $=16.33$ ) than learners in semester $1 / 2010$ (difference in mean scores $=12.88$ ).

The second question addressed here is the extent to which the learning gain as indicated by the pre-test/post-test difference is consistent with the results of the formal assessment process of the student for the blended course delivery. Firstly, the mean difference (Table II) between pre-test and post-test (paired difference) is significantly different at the $1 \%$ significance level $(p .=.005)$ from which it can be inferred that the blended learning environment supports learning achievement.

TABLE II: PAIRED DIFFERENCES BETWEEN PRE-TEST AND POST-TEST

\begin{tabular}{|c|c|c|c|c|c|c|}
\hline \multirow{2}{*}{ Pair } & \multicolumn{3}{|c|}{ Paired Differences } & & & Sig. \\
& Mean & $\begin{array}{c}\text { Std. } \\
\text { Deviation }\end{array}$ & $\begin{array}{c}\text { Std. Error } \\
\text { Mean }\end{array}$ & $t$ & $d f$ & 2-tailed \\
\hline $\begin{array}{l}\text { Pre-test }- \\
\text { Post-test }\end{array}$ & 16.33 & 19.188 & 4.954 & 3.297 & 14 & .005 \\
\hline
\end{tabular}

TABLE III: DETAILS OF NETSCORE, ALLTEST AND POST-TEST

\begin{tabular}{|c|c|c|c|c|}
\hline Score Types & Mean & $N$ & Std. Deviation & Std. Error Mean \\
\hline NetScore & 68.87 & 15 & 15.77460 & 4.07298 \\
\hline AllTest & 64.88 & 15 & 17.41771 & 4.49723 \\
\hline Post-test & 71.17 & 15 & 19.44811 & 5.02148 \\
\hline
\end{tabular}

TABLE IV: CORRELATION BETWEEN VARIOUS SCORE TYPES

\begin{tabular}{|ll|c|c|c|}
\hline \multicolumn{2}{|c|}{ Pair } & $N$ & Correlation & Sig. \\
\hline Pair 1 & Post-test \& NetScore & 15 & .705 & .003 \\
\hline Pair 2 & NetScore \& AllTest & 15 & .687 & .005 \\
\hline Pair 3 & AllTest \& Post-test & 15 & .685 & .005 \\
\hline
\end{tabular}

The third question concerns the validity of using the difference between pre and post scores as a measure of learning. The "NetScore" is the final score for grading the course based on the student's performance on all the required activities. "AllTest" is the average of every test score taken during the semester. Focussing on correlations between NetScore, AllTest and post-test score the results show that:

1) The mean of Post-test score $(\bar{x}=71.17)$ has a significant correlation (Spearman) with the NetScore $(\bar{x}=68.87)$ at a statistical level of $0.01(r=.705$, Sig. $=.003)$. This indicates that those who get a high course grade have a high post-test score (and vice versa).

2) The mean of AllTest $(\bar{x}=64.88)$ has a significant correlation (Spearman) with the NetScore $(\bar{x}=68.87)$ at a statistical level of $0.01(\mathbf{r}=.687$, Sig. $=.005)$. This indicates that those who get a high score averaged over all the test scores during the semester tend to have a high final score for grading and vice versa.

3) The mean of AllTest $(\bar{x}=64.88)$ has a significant correlation (Spearman) with the Post-test score $(\bar{x}=$ $71.17)$ at a statistical level of $0.01(\mathbf{r}=.685$, Sig. $=.005)$. This indicates that those who get a high score averaged over all the test scores during the semester tend to have a high post-test score and vice versa.

\section{CONCLUSION}

This work makes use of a 'Learner Model' in order to reflect back information about learning beliefs and activities. With respect to self-regulation - the way learners understand themselves, the better self-regulation the better the learning achievement. Combined with the use of Moodle LMS, this work has focused on how this kind of learning has an impact on learners to in their achievement comparing to the normal classroom learning with the same learning content.

The results here consists of :

1) What level of achievement was obtained with different learners in normal classroom learning, and also blended with the addition of online-learning focusing on a learner model. The results show that both groups of students have a mean post-test score which is higher than the mean for the pre-test score. This suggests that learners in both conditions have made learning gains. Moreover, focusing on the mean difference, the results indicate that learners in the blended learning environment have made a larger improvement (difference in mean scores $=16.33$ ) in their scores than learners in the normal classroom learning environment (difference in mean scores=12.88) with very similar learning content.

2) The learning information in the learner model proved useful through its reflection to either teachers or learners as to how well learners performed in terms of learning achievement. With the Moodle LMS, learning information during the semester of each particular student to assessments, homework, exercises and other activities carried out with their teacher and friends was kept and measured as "AllTest", which has an average mean score of 64.88 .

3) Comparing the learning achievement during a learning process to see whether there is any correlation among the various type of score from assignment and homework (AllTest) which has average mean score of 64.88 , Post-test which has average score of 71.17 and the final grading score (NetScore) which has average score of 68.87. The results (see Table 4) show that all of these score are significantly correlated to each other referred to the correlation value at the statistical level 0.01 for all comparison. Thus it can be inferred that this way of learning, through responsibility and self-regulation - the way of knowing themselves - for lesson activities of 
learners is a key factor for successful learning. Future work will seek to elucide the ways in which the open learner model is used by learners the ways in which it might be possible to support learners become better learners.

\section{REFERENCES}

[1] B. J. Zimmerman, "Self regulated learning and academic achievement: An overview," Educational Psychologist, vol. 25, no.1, pp. 3-17, 1990.

[2] B. J. Zimmerman, A. Bandura, and M. Martinez-Pons, "Self-motivation for academic attainment: The role of self-efficacy beliefs and personal goal setting," American Educational Research Journal, vol. 29, no. 3, pp. 663-676, 1992.

[3] N. M. Webb, "Peer interaction and learning in small groups," International Journal of Educational Research, vol. 13, no.1, pp. 21-39, 1989.

[4] D. W. Johnson and R. T. Johnson. "Cooperative, competitive, and individualistic learning environments," International Guide to Student Achievement, pp. 372-375, 2012.

[5] A. P. Rovai, "Development of an instrument to measure classroom community," Internet and Higher Education, vol. 5, no. 3, pp. 197-211, 2002.

[6] M. Martyn, "The hybrid online model: Good practice," Educause Quarterly, vol. 1, pp. 18-23, 2003.

[7] C. J. Bonk and C. R. Graham, Handbook of Blended Learning: Global Perspectives, Local Designs, San Francisco, CA: Pfeiffer Publishing, 2004, ch. 1.1.

[8] Bureau of International Cooperation. (2008). Towards a learning society in Thailand: An introduction to education in Thailand. Ministry of Education. [Online]. Available: http://www.bic.moe.go.th/th/images/stories/book/ed-eng-series/introed08.pdf

[9] S. Bull and T. Nghiem, "Helping learners to understand themselves with a learner model open to students, peers and instructors," in P. Brna and V. Dimitrova, Eds., Proc. Workshop on Individual and Group Modelling Methods that Help Learners Understand Themselves, International Conference on Intelligent Tutoring Systems, 2002, pp. 5-13

[10] V. G. Dimitrova, "STyLE-OLM: Interactive open learner modeling," International Journal of Artificial Intelligence in Education, vol. 13, pp. 35-78, 2003.

[11] S. Bull and H. Pain, "Did I say what I think I said, and do you agree with me?' Inspecting and questioning the student model," in J. Greer,
Ed., Proc. Artificial Intelligence in Education 1995, Washington, 1995, pp. 501-508.

[12] S. Bull and J. Kay, "Student models that invite the learner in: The SMILI:-) open learner modelling framework," IJAIED, vol. 17, no. 2, pp. 89-120, 2007.

[13] S. Bull and P. Gardner, "Raising learner awareness of progress towards UK-SPEC learning outcomes," Engineering Education: Journal of the Higher Education Academy Engineering Subject Centre, vol. 5, no. 1, pp. 11-22, 2010.

[14] N. Tongchai, "The impact of a group open learner model on learning in a computer-based collaborative learning environment," in Proc. Human Centred Technology Workshop 2006, 2006, pp. 7-10.

[15] N. Tongchai and P. Brna, "Enhancing metacognitive skills through the use of a group open learner model based on the zone of proximal development," in Proc. Workshop on Learner Modelling for Reflection, International Conference on Artificial Intelligence in Education 2005, 2005, pp. 91-98.

[16] G. Brown, J. Bull, and M. Pendlebury, Assessing Student Learning Higher Education, London: Routledge, 1997.

[17] G. Gibbs, "Improving the quality of student learning: Based on the improving student learning project by the council for national academic awards," Bristol: Technical and Education Services, 1992.

[18] W. R. Kulhavy and W. Wager, "Feedback in programmed instruction Historical context and implications for practice," in J. Dempsey and G. Sales, Eds., Interactive Instruction and Feedback, 1993, pp. 3-20, Englewood Cliffs, New Jersey: Educational Technology Publications.

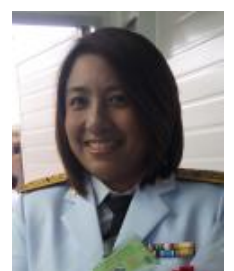

Nilubon Tongchai graduated with the $\mathrm{Ph} . \mathrm{D}$ (AI in education) from Glasgow University, UK in 2008, the Ms.C (computing) from Northumbria University, UK in 2001, and B.E. in computer from Khonkaen University, Thailand in 1998.

She works both as a lecturer in the Department of Computer Science, Faculty of Science and Technology and as a deputy director of the Academic Resources and Information Technology Centre at the same university. Her previous research concerned the application of computing technology in particular areas such as the application of blended online learning technology to enhance both individual and collaborative learning with concept of opening the learner model, the application of web-technology to help community members who work either as farmers or ones who have low income to have an opportunity to let the world know who they are, what they could do and know how to use internet technology to search for what they want to know which is life-long learning. 